\title{
Unintentional processing of motivational valence
}

\author{
Agnes Moors and Jan De Houwer \\ Ghent University, Ghent, Belgium \\ Dirk Hermans and Paul Eelen \\ University of Leuven, Leuven, Belgium
}

\begin{abstract}
Recent motivational affective priming studies (Moors \& De Houwer, 2001; Moors, De Houwer, \& Eelen, 2004) showed that primes that indicate success on a goal-inducing task facilitate positive target responses whereas primes that indicate failure on that task facilitate negative target responses. In the current studies, we examined whether these priming effects depend on consciously intentional processing of the motivational valence of the primes. In Experiment 1, the outcome of success or failure was presented not only immediately before the target (i.e., the prime) but also a second time after the target response. This should encourage participants to ignore the prime. In Experiment 2, participants were asked to respond to the targets within $600 \mathrm{~ms}$ after target onset. As a result, participants had little opportunity to process the motivational prime valence in a consciously intentional way. Nevertheless, strong affective priming effects were found in both studies. These results provide additional support for the claim that motivational valence can be processed without the conscious intention to do so.
\end{abstract}

Most appraisal theorists argue that evaluating the implications of an event for one's goals or concerns is a core antecedent for emotion elicitation (Frijda, 1986; Lazarus, 1991; Scherer, 1994). Whereas an appraisal component of goal relevance determines the intensity of the ensuing emotion (ranging from no emotion to emotions of increasing intensity), an appraisal component of motivational valence (Scherer's goal conduciveness or Lazarus' goal congruence) accounts for its raw positive-negative quality or the direction of its action tendency in terms of approach and withdrawal. ${ }^{1}$

Correspondence should be addressed to Agnes Moors, Department of Psychology, Ghent University, Henri Dunantlaan 2, B-9000 Ghent, Belgium. Email: agnes.moors@Ugent.be

Preparation of this manuscript was supported by Grant G.0326.01 from the Fund for Scientific Research (Flanders, Belgium) to Paul Eelen and Jan De Houwer and by Grant BOF 01101203 from the Special Research Fund to Jan De Houwer.

We would like to thank Klaus Rothermund for his suggestion to run Experiment 2.

${ }^{1}$ For the further refinement of positive and negative emotions into specific emotions such as happiness, pride, anger, fear, sadness, and shame, other appraisal components have been put forward such as type of concern, accountability, coping potential, and future expectancy, to name just a few. 
We distinguish motivational valence from intrinsic valence, as do a number of appraisal theorists (e.g., Ellsworth, 1991; Frijda, 1986; Orthony, Clore, \& Collins, 1988; Scherer, 1984). Intrinsic valence has been defined as a feature of the stimulus that may be innate or acquired but that is independent of the momentary goal state of the organism. In contrast, motivational valence is defined as a feature of the stimulus' relation to current goals or concerns. Stimuli that enhance goal attainment lead to positive evaluations; those that block or obstruct goal attainment lead to negative evaluations (Scherer, 1988). Rain may be positive for a farmer who wants to see his plants grow, but negative for someone who has set his mind on sunbathing. A food stimulus may be positive when a person is hungry, but negative when the person has eaten too much.

Both types of valence can be defined as contrasting with regard to the process responsible for producing the valence. Intrinsic valence can be conceptualized as stored valence, as a kind of valence tag associated to the memory representation of the stimulus and which may be retrieved upon stimulus encounter (cf. Fiske \& Pavelchak, 1986). Motivational valence, on the other hand, has been conceptualized as the result of a comparison between the encountered stimulus and a current desired state (as prescribed by goals or concerns), with a match leading to positive and a mismatch leading to negative evaluations (Frijda, 1986). Thus, intrinsic stimulus valence relies on the process of memory retrieval (activation of the memory trace leading to the representation of the stimulus and its associated valence tag), whereas motivational valence requires a comparison process to be operative or at least a process in which minimally two elements are activated, one for the actual, the other for the desired state. In order to determine motivational valence it is not sufficient to activate the memory representation of the encountered stimulus because an additional element, the desired state, is needed.

One implication of defining intrinsic and motivational valence in terms of the underlying generating process is that the boundary between both types of valence becomes very thin and may be easily crossed. Indeed, once the outcome of an appraisal of motivational valence has become stored in memory, it may be said to have become intrinsic, because on a subsequent encounter with that same stimulus, the stimulus-goal comparison process can be bypassed, and the previously stored valence can be directly retrieved from memory on the basis of the stimulus input alone. It should be noted that defining the difference between intrinsic and motivational valence in this way does not render intrinsic valence entirely independent of motivation. We reserve the term "intrinsic" for evaluations that do not require reference to a goal or concern at the time of evaluation. Such characterization leaves open the possibility that intrinsic valence was originally based on a stimulus-goal comparison.

Because both types of valence can be produced through different mechanisms they may coexist as two different aspects of a given stimulus. At a single moment in time, both types of valence may bear either overlapping or opposing valence signs. For example, a person's favorite food may have a positive intrinsic valence sign in memory, but depending on whether the person is hungry or has eaten too much of the food, the motivational valence of the food stimulus may be either compatible (positive) or incompatible (negative) with the intrinsic valence.

Although both components of appraisal produce an outcome in terms of raw positivenegative quality, most appraisal theorists do not accept intrinsic valence assessments as a sufficient antecedent for (most) emotions (Frijda, 1994; Lazarus, 1991; Scherer, 1994). For example, the word "cancer", although leading to a negative evaluation, is not likely to elicit a negative emotion unless it is appraised as relevant for and incongruent with one's own concerns (e.g., when the doctor announces that it is you that has cancer or someone that you love). 
Contemporary appraisal theorists conceive of appraisal as a cognitive process that can take place in an automatic fashion (e.g., Frijda, 1986, 1993; Lazarus, 1991; Scherer, 1993), and in this capacity appraisal can account for the sudden, spontaneous character of many emotions. It has been argued that if emotions are to play an adaptive role, they should be able to mobilize the organism in a fast, automatic sense (e.g., in order to act upon a potentially threatening situation). Therefore, if appraisal theorists want to maintain that appraisal is a necessary antecedent of all emotions, and therefore also of the quickly occurring ones, appraisal should be capable of taking place in a fast, automatic sense. More specifically, at least those appraisal components that are considered to be minimal prerequisites for emotion elicitation (i.e., goal relevance and motivational valence) should be able to take place in an automatic sense. The question of which appraisal components may be processed in an automatic sense awaits an empirical answer.

Whereas continuing empirical efforts have been undertaken to buttress the automatic character of the appraisal components of both goal relevance and intrinsic valence, support for an automatic appraisal of motivational valence is limited (e.g., Moors \& De Houwer, 2001; Moors, De Houwer, \& Eelen, 2004).

Support for the automatic detection of goal relevance mainly comes from attentional bias paradigms such as modified Stroop tasks or dot probe tasks demonstrating selective attention to goal-relevant compared to neutral stimuli (see Williams, Mathews, \& MacLeod, 1996). From the fact that goal-relevant stimuli exerted an influence on attention, it can be concluded that goal relevance was processed under the conditions created by the experiment. These conditions may indicate to a certain extent that the processing of goal relevance was automatic. ${ }^{2}$ For example, attentional bias effects that were obtained using a dot probe task with suboptimal cue presentation lend support to the idea that goal relevance may be processed automatically, in the sense of based on unconscious input (e.g., Mogg, Bradley, \& Williams, 1995). Note that the paradigms used in attentional bias research do not allow one to conclude whether beyond relevance, the valence of the stimuli was processed as well. In order to investigate whether valence is processed, one should make use of a paradigm that has the format of a priming paradigm, in which not only the valence of the primes (or cues) is manipulated (as is the case in the paradigms used to study attentional bias), but also the valence of the targets, so that congruence effects can be assessed.

The automatic processing of intrinsic stimulus valence is amply documented in previous affective priming and Simon research (Bargh, Chaiken, Govender, \& Pratto, 1992; De Houwer \& Eelen, 1998; Fazio, Sanbonmatsu, Powell, \& Kardes, 1986; Hermans, De Houwer, \& Eelen, 1994). Responses to a target stimulus are generally faster when the preceding prime shares the same intrinsic valence as the target (e.g., CANCER-WAR) than when prime and

\footnotetext{
${ }^{2}$ It is important to note that from different perspectives, theorists have put a different emphasis on different features of automaticity (such as efficient, unintentional, unconscious, uncontrollable, and fast). Whereas the early approach defined automaticity primarily in terms of efficiency (i.e., independence of attentional resources), more recent approaches distinguish between different types of automatic process, some dependent, others independent of attention, and retaining autonomy as the minimal criterion for automaticity (e.g., Bargh, 1992, 1997). Consistent with Bargh's view, we aim to investigate each automaticity feature separately. In addition, because we conceive of each automaticity feature as a continuum (also see Logan, 1985), we believe it is justified to adduce arguments in favour of the presence of these features even when these arguments do not demonstrate the total presence or absence of these features.
} 
target valence are opposite (e.g., FLOWER-WAR). The occurrence of an affective priming effect indicates that the primes must have been evaluated under the conditions created by the experiment. These conditions are informative about which automaticity features apply to the process responsible for evaluation of the primes. This evaluation process has been shown to be rapid (e.g., Fazio et al., 1986; Hermans et al., 1994; Hermans, De Houwer, \& Eelen, 2001; Klauer, Roßnagel, \& Musch, 1997), to be triggered without conscious intentions (Bargh, Chaiken, Raymond, \& Hymes, 1996; Hermans et al., 1994; but see Klauer \& Musch, 2001; Spruyt, Hermans, De Houwer, \& Eelen, 2002), to be relatively efficient (e.g., Hermans, Crombez, \& Eelen, 2000), and to act on unconscious stimulus input (e.g., Draine \& Greenwald, 1998). Standard affective priming effects yield support for the automatic processing of intrinsic valence, but not of motivational valence because the prime stimuli used in these studies were often words or pictures for which participants most likely possessed a pre-established positive or negative valence in memory, and the motivational context was kept equal across conditions.

In another type of priming study, the primes conveyed feedback of performance on a prior trial (e.g., Derryberry, 1988; Rothermund, 2003). For example, Rothermund asked participants to evaluate target words prior to a fixed response deadline. Next, a feedback stimulus (a smiling or sad schematic face) indicated whether the target response was successful (i.e., both correct and in time) or not. This feedback stimulus was treated as the prime stimulus for the target of the next trial, and in this way cross-trial priming effects could be assessed. ${ }^{3}$ Despite the fact that primes signalled goal attainment, these experiments do not provide an adequate operationalization of motivational valence. This is because smiling and sad schematic faces probably possessed a fixed positive or negative valence in the participants' memory prior to the experiment. As a consequence, during the experiment, the valence of the primes could be determined via memory retrieval so that no stimulus-goal comparison had to be performed. We do not mean to suggest that computation of motivational valence is excluded in studies that keep stimulus valence fixed throughout the entire experiment, because it cannot be excluded that activated intrinsic valence tags become related to the person's concerns or goals after all. However, in these studies, one cannot be certain that an interaction with goals occurred, because a simple memory retrieval process might have produced a valence outcome and hence might have been responsible for (cross-trial) priming effects. In sum, when the purpose is to demonstrate that valence other than intrinsic valence can be processed in an automatic sense, one should prevent primes from acquiring a fixed valence tag in memory. One way to achieve this is by manipulating the desired state from trial to trial (see further).

Given the central role that the appraisal of motivational valence plays in emotion elicitation (in contrast to the appraisal of intrinsic valence), it is crucial to establish evidence in favour of the hypothesis that appraisal of motivational valence can be processed in an automatic sense. Arguably, emotional responses must not only be elicited in a fast, automatic sense in order to be adaptive, they should also be flexible. More in particular, they should take into account the motivational state of the subject at the time of stimulus encounter and not have to rely solely on evaluations that have been made in the past. On some occasions, relying on past solutions may be beneficial, but on other occasions, it may steer the subject in the wrong direction (e.g., in cases where intrinsic and motivational valence are not

\footnotetext{
${ }^{3}$ These studies were not about automatic processing of prime valence, as prime durations were very long.
} 
compatible). Emotions are adaptive when they are at the service of goals and well-being, and goals may vary across situations. Admittedly, some source goals that are situated high up the goal hierarchy remain fairly constant throughout a person's life. However, subgoals that are at the service of these higher order goals may vary to a great extent, even from one moment to another. For example, physical well-being is a concern that may be expected to remain fairly stable throughout a person's life. At some moments, however, this concern may require the subgoal to consume food, at other moments, it may require the subgoal to stop eating.

In order to investigate the automatic nature of the appraisal of motivational valence, we developed a variant of the sequential affective priming procedure (Moors \& De Houwer, 2001) in which the intrinsic valence of the primes was kept neutral whereas their motivational valence was manipulated as follows. On each trial, a goal-inducing phase preceded the presentation of prime and target. During this goal-inducing phase, a game rule stipulated a rewarded colour ("yellow $=10$ points" or "blue $=10$ points"), and participants engaged in a computer task in which they tried to gain the rewarded colour. During the priming phase, the colour (yellow or blue) of an intrinsically neutral prime stimulus (a row of $X \mathrm{~s}$ ) was introduced as the outcome of the goal-inducing task. We therefore assumed that the motivational valence of this prime was positive when its colour corresponded to and negative when it differed from the rewarded colour. The prime $(200 \mathrm{~ms})$ was followed by an intrinsically positive or negative target word (SOA of $300 \mathrm{~ms}$ ), which participants were requested to evaluate. Most importantly, we varied the rewarded colour from trial to trial in a random fashion. In this way, participants were prevented from attaching a fixed valence to the memory representations of each colour. In order to evaluate the primes, participants could thus not rely on stored valence, but were instead obliged to make a comparison between the rewarded colour and the prime colour on each trial. Moors and De Houwer (2001) repeatedly found superior performance (faster response times and fewer errors) on trials with an overlap between motivational prime valence and intrinsic target valence compared to trials on which both types of valence were opposite. From the fact that motivational prime valence influenced the target responses resulting in a priming effect, we inferred that the motivational prime valence must have been processed under the conditions created by the experiment.

Analysing these conditions provides information about which automaticity features (e.g., Bargh, 1994; Logan, 1988; Shiffrin, 1988) pertain to the processing of motivational valence. For instance, with respect to our former studies, the fact that the motivationally relevant information was presented briefly before the target demonstrates the rapid onset of the processing of motivational valence. The purpose of the current research was to strengthen the case for the automatic nature of the appraisal of motivational valence, by furnishing arguments for its unintentional character as well. It is probably more accurate to say that we attempted to demonstrate that motivational valence can be processed without the conscious intention to process it. ${ }^{4} \mathrm{By}$ its very nature, the processing of motivational valence is

\footnotetext{
${ }^{4}$ We do not aim to rule out that processing of motivational valence is not mediated by an unconscious goal to process motivational valence, for this seems virtually impossible. With respect to terminology, it should be noted that whereas according to some authors, the term "intentional" implies the conscious choice of a processing goal, we prefer using the term "intentional" merely to indicate that the process was produced by the subject's goal to engage in the process, irrespective of whether this goal was consciously or unconsciously activated. Because we do not share the position that the term "intentional" includes "consciousness", we consistently speak about "conscious intentions" or "without conscious intentions".
} 
goal-dependent. Because motivational valence is the result of a comparison between the actual situation and a desired situation prescribed by some goal or concern, motivational valence can only be present and thus processed when that goal or concern is active. The fact that the processing of motivational valence is by definition goal-dependent does not imply, however, that it is intentional as well. Goal-dependent processes depend on some goal to be operative. The process is intentional only when that goal is directed at engaging in the process under consideration. When the process under consideration is not the focus, but instead an unintended consequence of other intended processes, the process qualifies as an unintentional goal-dependent process (Bargh, 1989).

With regard to the motivational priming paradigm of Moors and De Houwer (2001), one can make a distinction between the (conscious) goal to gain the rewarded colour and the (conscious) goal to verify whether the rewarded colour was indeed obtained (i.e., processing the prime valence). If priming can occur without the second conscious goal being active, the processing of motivational prime valence meets the criteria for a process that is not consciously intentional. In normal circumstances, however, one would expect the second conscious goal to follow naturally from the first conscious goal. In addition to this natural inclination to verify whether goals are obtained, participants may have been motivated to process the outcome of the goal-inducing task as part of a strategy to improve their future performance on that task (the strategy to learn from one's mistakes). The only argument for participants to abandon the conscious goal to verify their outcome on the goal-inducing task comes from the fact that focusing on this outcome is disadvantageous for the task to respond to the targets as quickly as possible. In order to find additional support for the idea that processing of motivational valence can take place without the conscious goal to do so, we examined whether motivational priming effects can also be observed under conditions that more strongly discourage or interfere with the consciously intentional processing of motivational prime valence.

\section{EXPERIMENT 1}

Because it seems difficult to eliminate the conscious goal to verify the outcome on the goalinducing task without also removing the conscious goal to gain the rewarded colour, we tried to find a way to direct the participants' focus away from the motivational prime valence without forcing them to abandon the conscious goal to verify their outcome. This could be achieved by giving participants a second opportunity to verify their outcome on the goal-inducing task at a moment other than the moment of prime presentation. Experiment 1 was identical to the motivational priming study of Moors and De Houwer (2001), except that the outcome of the goal-inducing task was not only shown before (i.e., the prime) but also after the target response was given (i.e., a repeated outcome stimulus identical to the prime). As a result, participants had ample opportunity to verify their performance on the goal-inducing task after responding to the target, so that they would no longer feel compelled or have the conscious intention to do so at the time of prime presentation. We predicted superior performance on trials on which motivational prime valence and intrinsic target valence were congruent as compared to trials on which both types of valence were incongruent. Such a result would provide further support for the idea that motivational valence can be processed independent of the conscious intention to do so. 


\section{Method}

\section{Participants}

A total of 30 undergraduate psychology students (6 men, 24 women) at the University of Leuven participated in this experiment in order to partially fulfil course requirements. They were all native Dutch speakers.

\section{Materials}

Both prime stimuli and feedback stimuli were a series of five Xs. Target stimuli were positive and negative adjectives chosen from the Dutch affective rating list of Hermans and De Houwer (1994; cf. Appendix). All stimuli were presented in the centre of a black 70-Hz SVGA screen connected to an IBM-compatible 386 computer. A voice key registered the time between the onset of the target and the onset of the verbal response by generating a signal that stopped a highly accurate (beyond $1 \mathrm{~ms}$ ) Turbo Pascal Timer (Bovens \& Brysbaert, 1990). Participants were seated at a distance of approximately $60 \mathrm{~cm}$ from the computer screen.

\section{Procedure}

Participants took part on an individual basis and received oral instructions about the course of the experiment. They were presented with a total of 176 trials: 16 practice trials and 160 experimental trials. On each trial the presentation of the prime-target pair was preceded by a goal-inducing phase. At the onset of the goal-inducing phase, one out of two game rules appeared on screen. One rule stipulated that the colour yellow would yield 10 points, whereas the other rule indicated that blue would provide 10 points. Game rules varied across trials in a random order. One second after onset of the game rule, the letters $\mathrm{Y}$ (designating yellow) and $\mathrm{B}$ (designating blue) were displayed in quick alternating succession (letters replaced each other after approximately $140 \mathrm{~ms}$ ). ${ }^{5}$ Participants were instructed to attempt to press the space bar of the keyboard at the exact moment at which the first letter of the rewarded colour for that particular trial was on screen. This phase was presented to the participants as a skill game. The game rule remained on screen until the space bar was pressed. After onset of the keypress response, both letters were presented simultaneously for another $200 \mathrm{~ms}$ in order to prevent participants from noticing the last letter that remained on screen (i.e., the one they had actually pressed). Hence, at this stage, participants received no feedback about their performance on the goal-inducing task yet.

The prime stimulus was a row of five $X$ s printed in either yellow or blue. It was presented $550 \mathrm{~ms}$ after the letters of the goal-inducing task disappeared, and it remained on screen during $200 \mathrm{~ms}$. Participants were told that the prime colour corresponded to the letter that was actually hit due to their keypress response. In this way, the prime colour was said to reflect their outcome on the goal-inducing task. In reality, however, the prime colour was determined independent of the moment at which the participants pressed the space bar. Rather, it corresponded to the rewarded colour on only half of all trials. Due to the fact that the letters alternated very quickly during the goal-inducing task and that the last letter (the one they had actually pressed) was masked by the simultaneous presentation of both letters, participants were unable to notice that there was no relation between their keypress responses and the colour of the primes. Motivational prime valence was positive when the prime colour and the rewarded colour were the same (i.e., outcome of success) and negative when they differed (i.e., outcome of failure). It should be emphasized that the only way through which participants received feedback at

\footnotetext{
${ }^{5}$ Because our participants were Dutch, the game rules were presented in Dutch ("geel" = 10, "blauw" =10) as were the alternating letters $(\mathrm{G}, \mathrm{B})$ that indicated the colours.
} 
this stage was via the prime. After $100 \mathrm{~ms}$, the prime was followed by a target word with either a positive or a negative intrinsic valence. The stimulus-onset asynchrony (SOA) was thus $300 \mathrm{~ms}$. Participants were instructed to evaluate the target as fast as possible by saying aloud "POSITIVE" or "NEGATIVE" in the microphone of the voice key. Target words remained on screen until a response was registered or $3,000 \mathrm{~ms}$ elapsed. At $500 \mathrm{~ms}$ after the experimenter had pressed a code indicating the kind of response the participant had given (positive, negative, or a separate code for voice key failures), a second outcome stimulus appeared on screen during $1,500 \mathrm{~ms}$. On each trial, the repeated outcome stimulus was identical to the prime stimulus. The intertrial interval was $1,000 \mathrm{~ms}$. The experiment was interrupted for short breaks after the practice trials as well as after every 40 experimental trials. At the end of the experiment, participants received a fictitious game score.

We manipulated rewarded colour (yellow vs. blue), prime colour (yellow vs. blue), and intrinsic target valence (positive vs. negative) resulting in an eight-cell within-subjects design. Within the 16 practice trials, all eight cells were presented two times in random order. Each of the 16 practice targets appeared once in the 16 practice trials. The 160 experimental trials were divided in four blocks of 40 trials. Within each block, all eight cells were presented five times. Each of the 20 experimental targets appeared twice in the 40 experimental trials of each block. Both practice and experimental targets were assigned randomly to their corresponding cells. Within blocks, trials were presented in random order with the following restrictions: (a) The rewarded colour could be the same on no more than six consecutive trials; (b) the prime colour could be the same on no more than four consecutive trials; and (c) target valence could be the same on no more than four consecutive trials. As dependent variables, reaction times as well as numbers of errors for evaluating the targets were measured.

\section{Results}

Practice trials, trials on which reaction times were shorter than $150 \mathrm{~ms}$ or longer than $2,000 \mathrm{~ms}(0.52 \%)$, and trials on which the experimenter noticed problems with the voice key $(3.92 \%)$ were excluded from all analyses. For the remaining trials, mean reaction times as well as numbers of errors were calculated for each participant. For the calculation of the mean reaction times, trials on which an incorrect target response was given $(5.39 \%)$ were not included. Analyses of variance (ANOVAs) were conducted on the mean reaction times and mean numbers of errors separately, using motivational prime valence (positive vs. negative) and target valence (positive vs. negative) as within-subjects variables.

The ANOVA of the mean reaction times revealed a significant interaction between motivational prime valence and intrinsic target valence, $F(1,29)=21.51, M S E=551.42, p<.01$. Table 1 shows shorter reaction times on trials with congruent prime and target valence than on trials with incongruent prime and target valence. Further, we found significant main effects for motivational prime valence, $F(1,29)=9.67, M S E=1,116.26, p<.01$, as well as for intrinsic target valence, $F(1,29)=20.13, M S E=1,802.13, p<.01$. These main effects entail shorter response times for trials with positive primes $(M=614, S D=81)$ than for trials with negative primes $(M=633, S D=91)$ as well as shorter response times for trials with negative targets $(M=607, S D=81)$ than for trials with positive targets $(M=641, S D=93)$. Table 1 suggests that the effect of congruence was limited to trials on which a positive target was presented. However, this could be due to the fact that reaction times were overall slower when the motivational valence of the prime was negative, which counteracts the effect of congruence on trials with negative targets, but adds to the effect of congruence when targets are positive. 
TABLE 1

Mean reaction times ${ }^{a}$ and mean numbers of errors as a function of motivational prime valence and intrinsic target valence in Experiment 1

\begin{tabular}{|c|c|c|c|c|c|}
\hline & \multirow[b]{3}{*}{ Intrinsic target valence } & \multicolumn{4}{|c|}{ Motivational prime valence } \\
\hline & & \multicolumn{2}{|c|}{ Positive } & \multicolumn{2}{|c|}{ Negative } \\
\hline & & $M$ & $S D$ & $M$ & $S D$ \\
\hline \multirow{2}{*}{ Reaction times } & positive & 622 & 92 & 661 & 101 \\
\hline & negative & 607 & 78 & 606 & 86 \\
\hline \multirow[t]{2}{*}{ Errors } & positive & 2.97 & 2.47 & 2.77 & 2.76 \\
\hline & negative & 2.06 & 2.18 & 1.33 & 1.47 \\
\hline
\end{tabular}

${ }^{\mathrm{a}}$ In ms.

The ANOVA of the mean numbers of errors failed to produce a significant interaction between motivational prime valence and intrinsic target valence, $F<1$. Only a significant main effect of target valence was found, $F(1,29)=11.94, M S E=3.42, p<.01$, with fewer errors on trials with negative targets $(M=1.70, S D=1.57)$ than on trials with positive targets $(M=2.87, S D=2.27)$. Finally, there was a marginally significant main effect of motivational prime valence, $F(1,29)=3.08, M S E=2.12, p<.09$, with fewer errors on trials with negative primes $(M=2.05, S D=1.88)$ than for those with positive primes $(M=2.52, S D=1.86)$.

\section{Discussion}

We obtained a priming effect for the reaction time data, with faster responses on trials with an overlap between intrinsic target valence and motivational prime valence than on trials in which both types of valence differed. The fact that priming occurred despite an SOA of $300 \mathrm{~ms}$ pleads for the rapid onset of motivational prime valence. One can also argue that the results support the idea that motivational prime valence can be processed without the conscious intention to process it: Participants were given two opportunities to verify whether the rewarded colour was obtained: one time before (i.e., prime) and one time after (i.e., repeated outcome stimulus) the target response was given. Two features of the procedure may have stimulated participants to concentrate on the repeated outcome stimulus rather than on the prime. First, focusing on the prime valence would interfere with the task to respond as quickly as possible to the targets. Second, the presentation duration of the repeated outcome stimulus $(1,500 \mathrm{~ms})$ clearly exceeded that of the prime $(200 \mathrm{~ms})$, which should make it much easier to derive feedback from the outcome stimulus than from the prime. It was thus advantageous for the participants to ignore the primes and derive feedback from the repeated outcome stimulus. There was also no disadvantage attached to ignoring the prime. Because participants had ample time to verify the feedback about their performance on the goal-inducing task at the end of each trial, ignoring the prime did not imply a loss of feedback about that performance. 


\section{EXPERIMENT 2}

In the priming literature, it has been suggested that short SOAs do not allow for consciously intentional, strategic processes to operate (e.g., Bargh, 1997; Neely, 1977). Although it may not be unreasonable to think that consciously intentional processes are time-consuming, a short SOA as such does not prevent time-consuming processes from taking place, not even when it is close to zero. This is because participants may, in addition to the time between prime and target, also use part of the time between the target and the response to process the prime valence in a consciously intentional way before processing and responding to the targets. One way to solve this problem is to combine a short SOA with a short response deadline. This is exactly what we did in our second experiment. We assumed that the short processing time thus available would encourage participants to abandon the conscious goal to verify their outcome on the goal-inducing task, because dwelling on the prime entailed the risk of responding too late to the targets. Even if participants would not be persuaded to abandon the conscious goal to verify their outcome, implementation of that goal would have become very difficult (at least when target responses were given prior to the deadline). In sum, imposing a response deadline may discourage or hinder consciously intentional processing of the motivational prime valence.

Except for the response deadline, Experiment 2 was identical to the first priming study of Moors et al. (2004) in which game rules stipulated a rewarded category ("animal $=10$ points" or "profession $=10$ points"), and primes were words chosen from a list of 20 animal exemplars (e.g., walrus) and 20 profession exemplars (e.g., detective). The reason why we adapted this variant of the motivational affective priming paradigm instead of the colour variant is that less time is needed to process perceptual features such as colour than semantic features such as semantic category. By selecting semantic category as the motivationally relevant prime feature, we thus further reduced the likelihood that participants would be able to process the motivational valence of the primes in a consciously intentional fashion. We chose to install the response deadline $600 \mathrm{~ms}$ after target onset, which was respectively $28 \mathrm{~ms}(0.38 S D)$ and $40 \mathrm{~ms}$ $(0.54 S D)$ lower than the mean reaction times on the congruent and incongruent trials in Study 1 of Moors et al. (2004).

\section{Method}

\section{Participants}

A total of 26 undergraduate economics students (13 men, 13 women) at the University of Leuven participated in this experiment in exchange for course credits. They were all native Dutch speakers.

\section{Materials}

Prime words for the practice trials were six animal exemplars and six profession exemplars. For the experimental trials, we used 20 other animal exemplars and 20 other profession exemplars. Target stimuli for the practice trials were eight positive and eight negative nouns. For the experimental trials, 10 other positive and 10 other negative nouns served as targets. All target words were chosen from the Dutch affective rating list of Hermans and De Houwer (1994). Results of $t$ tests showed that positive and negative experimental targets differed significantly on the affective dimension, $t(18)=25.75$, $p<.01$, but not with respect to the affective extremity of the words, nor with respect to the number of 
letters, all $t \mathrm{~s}<1$. (See Appendix for a list of all experimental stimuli.) Other aspects of the presentation of the stimuli and the registration of the responses were the same as those in Experiment 1.

\section{Procedure}

We describe only the differences with Experiment 1. The goal-inducing phase was identical to the goal-inducing phase of Experiment 1 except that the game rules were "animal $=10$ " and "profession $=10$ ", and the alternating letters were A (indicating animal) and $\mathrm{P}$ (indicating profession). ${ }^{6}$ Also, the alternating letters were displayed two seconds after presentation of the game rule (compared to one second in Experiment 1) in order to reduce the risk that participants would ignore the game rule of the goal-inducing task. During the priming phase, the prime word could be either an animal exemplar (e.g., walrus) or a profession exemplar (e.g., radiologist). Motivational prime valence was positive when the prime was an exemplar of the rewarded category (i.e., when 10 points were won) and negative when it was not an exemplar of the rewarded category (i.e., when no points were won). Participants were requested to evaluate the subsequently presented target word by saying aloud "POSITIVE" or "NEGATIVE" within $600 \mathrm{~ms}$ after target onset. The target disappeared automatically from the screen after $600 \mathrm{~ms}$ unless a response was registered before that time. In the latter case, the colour of the target word turned from white to red, and the word remained on screen during another $200 \mathrm{~ms}$ after onset of the target response. In order to motivate participants to respond in time, we told them that target responses made prior to the response deadline would yield an extra point, whereas target responses made after that time would cost one point. We kept the reward (and cost) for this task relatively low compared to the reward for the goal-inducing task so as to prevent participants from losing interest in the goal-inducing task. After the experimenter had pressed the key for coding the kind of response the participant had given, there was an interval of $700 \mathrm{~ms}$ before the next trial began. At the end of the experiment, we asked participants whether they had been able to determine their outcome on the goal-inducing task. In this way we wanted to verify whether we had succeeded in making it difficult for participants to process the prime valence in a consciously intentional fashion with the present procedure. On the basis of this interview, the experimenter classified participants according to whether they said that they were (a) almost never aware, (b) sometimes aware, or (c) most often aware of the motivational valence of the primes.

\section{Results}

Practice trials, trials with voice key errors (5.07\%), and trials on which reaction times were shorter than $150 \mathrm{~ms}$ or longer than the response deadline (i.e., $600 \mathrm{~ms} ; 14.47 \%$ ) were discarded from all analyses. For each participant, mean reaction times as well as numbers of errors were calculated. Trials on which an incorrect response was given $(6.33 \%)$ were left out of the calculation of the mean reaction times. ANOVAs were conducted separately for the mean reaction times and the mean numbers of errors, with motivational prime valence (positive vs. negative) and intrinsic target valence (positive vs. negative) as within-subjects variables.

The ANOVA of the mean reaction times revealed a significant interaction between motivational prime valence and intrinsic target valence, $F(1,25)=4.49, M S E=247.54, p<.05$. Table 2 shows that reaction times were shorter on trials with congruent prime and target

\footnotetext{
${ }^{6}$ Again the game rules and the alternating letters of the goal-inducing task were presented in Dutch (“dier" = 10, "beroep" = 10, D, B).
} 
TABLE 2

Mean reaction times ${ }^{\mathrm{a}}$ and mean numbers of errors as a function of motivational prime valence and intrinsic target valence in Experiment 2

\begin{tabular}{|c|c|c|c|c|c|}
\hline & \multirow[b]{3}{*}{ Intrinsic target valence } & \multicolumn{4}{|c|}{ Motivational prime valence } \\
\hline & & \multicolumn{2}{|c|}{ Positive } & \multicolumn{2}{|c|}{ Negative } \\
\hline & & $M$ & $S D$ & $M$ & $S D$ \\
\hline \multirow[t]{2}{*}{ Reaction times } & positive & 502 & 30 & 516 & 35 \\
\hline & negative & 509 & 24 & 510 & 27 \\
\hline \multirow[t]{2}{*}{ Errors } & positive & 1.04 & 1.11 & 2.42 & 2.73 \\
\hline & negative & 3.12 & 2.73 & 1.58 & 1.75 \\
\hline
\end{tabular}

an ms.

valence than on trials with incongruent prime and target valence. Furthermore, a significant main effect was found for motivational prime valence, $F(1,25)=7.31, M S E=210.46, p<.05$, entailing shorter response times for trials with positive $(M=505, S D=23)$ than for trials with negative motivational prime valence $(M=513, S D=26)$.

The ANOVA of the mean numbers of errors also revealed a significant interaction between motivational prime valence and intrinsic target valence, $F(1,25)=20.43, M S E=2.72$, $p<.01$. Table 2 shows fewer errors on trials with congruent prime and target valence than on trials with incongruent prime and target valence. Furthermore, a significant main effect was found for target valence, $F(1,25)=4.77, M S E=2.07, p<.05$, with fewer errors on trials with positive targets $(M=1.73, S D=1.71)$ than on trials with negative targets $(M=2.35$, $S D=2.13)$.

A total of 15 participants reported that they were almost never aware of the feedback provided by the prime. Several of these participants said that there was no time to find out whether the prime belonged to the rewarded category or not and that they therefore did not pay attention to it. Some of them also declared that whenever they did try to determine the prime valence, they were unable to respond to the target in time. It was to avoid including this type of late target response that we discarded reaction times longer than $600 \mathrm{~ms}$ from our analyses. A total of 10 other participants reported that they were aware of the prime valence most of the time. One participant reported having captured the prime valence half of the time. In order to create one unaware and one aware group, the latter participant was added to the aware group. For each dependent variable, we conducted an additional ANOVA in which we included the reported valence awareness of the primes (unaware vs. aware) as a between-subjects variable and again motivational prime valence (positive vs. negative) and intrinsic target valence (positive vs. negative) as the within-subjects variables. Adding the reported valence awareness as a variable did not eliminate the overall interaction effect between motivational prime valence and intrinsic target valence for the latency data, $F(1,24)=4.26$, $M S E=257.79, p=.05$, or the error data, $F(1,24)=23.49, M S E=2.56, p<.01$. More importantly, for neither of the dependent variables was the three-way interaction between reported valence awareness, motivational prime valence, and intrinsic target valence significant: $F<1$ for the reaction time data, and $F<2.54(p<.13)$ for the error data. The relevant 
TABLE 3

Mean reaction times ${ }^{\mathrm{a}}$ and mean numbers of errors as a function of motivational prime valence and intrinsic target valence for both unaware and aware participants in Experiment 2

\begin{tabular}{|c|c|c|c|c|c|c|c|c|c|}
\hline & \multirow[b]{4}{*}{ Target valence } & \multirow{2}{*}{\multicolumn{4}{|c|}{$\begin{array}{l}\text { Unaware group }(N=15) \\
\text { Motivational prime valence }\end{array}$}} & \multicolumn{4}{|c|}{ Amare group $(N=11)$} \\
\hline & & & & & & \multicolumn{4}{|c|}{ Motivational prime valence } \\
\hline & & \multicolumn{2}{|c|}{ Positive } & \multicolumn{2}{|c|}{ Negative } & \multicolumn{2}{|c|}{ Positive } & \multicolumn{2}{|c|}{ Negative } \\
\hline & & $M$ & $S D$ & $M$ & $S D$ & $M$ & $S D$ & $M$ & $S D$ \\
\hline \multirow[t]{2}{*}{ Reaction times } & positive & 503 & 24 & 519 & 35 & 499 & 37 & 512 & 36 \\
\hline & negative & 513 & 27 & 516 & 30 & 503 & 20 & 502 & 19 \\
\hline \multirow[t]{2}{*}{ Errors } & positive & 1.00 & 1.07 & 1.60 & 1.40 & 1.09 & 1.22 & 3.55 & 3.67 \\
\hline & negative & 2.80 & 1.94 & 1.33 & 1.50 & 3.55 & 3.62 & 1.91 & 2.07 \\
\hline
\end{tabular}

${ }^{\mathrm{a}}$ In ms.

means of these interactions can be found in Table 3. For the error data, planned comparisons showed a significant interaction between motivational prime valence and target valence for the participants that reported no valence awareness, $F(1,24)=6.25, M S E=2.56, p<.05$, as well as for participants that reported some or more valence awareness, $F(1,24)=17.97$, $M S E=2.56, p<.01$. For the reaction time data, planned comparisons did not reach significance for either level of reported valence awareness: $F<2.34(p<.14)$ for the unaware group, and $F<1.98(p<.17)$ for the aware group.

\section{Discussion}

In Experiment 2 we obtained overall priming effects for both the reaction time data and the error data, despite the fact that a $600-\mathrm{ms}$ response deadline was installed that made consciously intentional focusing on the motivational prime valence difficult to combine with responding to the target prior to that deadline. A total of 15 out of 26 participants reported that they were not aware of the motivational prime valence but they nevertheless showed a priming effect for the error data. Moreover, this effect was comparable to that observed in participants who reported that they were most often aware of the feedback provided by the prime. Because we assume that a lack of awareness of the prime valence indicates that either the conscious intention was abandoned to process the prime valence or the conscious intention to process the prime valence could not be implemented, the present results suggest that appraisal of motivational valence can take place automatically, in the sense of without the conscious intention to engage in it.

Priming was stronger for the error data than for the latency data. This is in line with what one would expect when a response deadline or response window is used. The use of a (narrow) response window decreases the variability in the latency data, which on the basis of a supposed speed-accuracy trade-off function results in an increased variability in the error data. In this way, the use of a response window creates maximal opportunity for priming effects to be revealed in the error data. The window widths used in other priming studies 
(e.g., Draine \& Greenwald, 1998) usually tend to be smaller than the one used in our study. It is therefore not surprising that we still found priming effects for the reaction time data over both groups of participants. It must be noted, however, that our motivation to use a response deadline was not to increase the variability in the error data, but to give participants little time to concentrate on the motivational prime valence.

In order to further increase the number of participants that are unable to focus on the motivational prime valence, one might propose to further decrease the amount of processing time at their disposal. However, both reducing the SOA between prime and target (and/or the prime duration) or shortening the response deadline may hinder the occurrence of a priming effect. First, when primes are no longer visible, as with suboptimal prime durations, participants risk losing interest in the goal-inducing task. The same risk exists when the deadline for evaluating the targets is made shorter. The target task may then become so absorbing that participants shift their energy completely towards that task and, as a result, ignore the game rules of the goal-inducing task. If participants lose interest in the goal-inducing task and thus no longer consider the rewarded stimulus as goalrelevant, manipulation of the motivational prime valence is unsuccessful, and priming cannot possibly occur.

Second, the use of short SOAs and suboptimal prime durations may also damage the successful manipulation of motivational prime valence in a more subtle way. Even if shortening SOAs and prime durations would not make participants ignore the goal-inducing task, it may still be possible that participants stop considering the primes as conveying feedback about performance on that task. That is, participants may not consider the primes as relevant for their goals, and it may turn out that perceiving a certain stimulus as relevant for one's concerns is a critical condition for engaging in the computation of the motivational valence of that stimulus. In other words, stimuli that are not perceived as relevant for a certain goal may not receive an evaluation in function of that goal. Note that there is a subtle difference between considering a certain output as relevant for one's goal state and actually computing whether that output matches or mismatches one's goal state. It may well be that in our priming studies, primes had to be regarded as feedback (thus, as relevant) but that the actual computation of valence could take place without the conscious intention to do so. In other words, the processing of motivational prime valence may have been independent of conscious intentions, but not of perceived relevance.

We actually conducted an experiment that was similar to Experiment 1 except that the colour of the prime and the colour of the repeated outcome stimulus corresponded on only half of all trials, and participants were told that only the latter stimulus yielded feedback about their performance on the goal-inducing task. No priming effects were found in this experiment, which might indicate that primes must be regarded as feedback in order to remain motivationally relevant and to produce a priming effect.

In sum, creating variants of the motivational affective priming paradigm to demonstrate that motivational prime valence can be processed without conscious intentions is always an exercise of balance between giving little opportunity for consciously intentional processing to occur and at the same time keeping the motivational valence of the primes intact. The manipulation of motivational prime valence fails when the goal to gain points is no longer active or when the primes are no longer considered to provide feedback about achievement of that goal. 


\section{GENERAL DISCUSSION}

The aim of the present experiments was to test whether motivational stimulus valence can be processed automatically in the sense of independent of conscious intentions. Results showed priming of motivational valence even when consciously intentional processing of motivational prime valence was strongly discouraged or made very difficult. The present results therefore suggest that processing of goal achievement information may also occur without the conscious intention to do so.

One might argue that, in real life, the conscious activation of a goal spontaneously leads to the conscious intention to determine whether the goal was achieved. It can therefore be questioned whether the processing of motivational valence without conscious intentions corresponds to an ecologically valid reality. Two remarks seem relevant in this respect. First, in Bargh's (1989) taxonomy of automatic processes, there is room for intentional processes that are nevertheless automatic. Intentional processes are automatic when they are autonomous, a feature they share with all other types of automatic process. Bargh (1992) defines an autonomous process as a process that, once initiated (either intentionally or unintentionally), runs to completion without conscious guidance. Consistent with this taxonomy, we argue that even if in natural circumstances, the processing of motivational valence would be triggered by a (conscious) intention, it may still be autonomous. Even when subjects are eager to know whether a goal was achieved and therefore trigger the processing of motivational valence in a consciously intentional sense, the procedure that compares the actual and the rewarded stimulus may take place without conscious monitoring, and the computational rules that are followed may remain impenetrable. Especially in real life, where goals are part of a complex goal hierarchy, and events can bear relevance to more than one goal or concern at the same time, it would be adaptive for organisms to have an autonomous mechanism that evaluates and weighs the expected consequences of events for these goals. Because we consider it unlikely that when the processing of motivational valence is triggered without conscious intentions, it would nevertheless require conscious guidance to run to completion, the results suggesting that appraisal of motivational valence can be triggered without conscious intentions also suggest that it can proceed in an autonomous fashion.

Second, even in real life, the goal to process motivational valence is probably not always consciously active. Especially when a person is not aware of the desired situation (as is the case for latent concerns or standards), he or she will not actively search to verify whether an encountered stimulus matches this unconscious desired situation. For example, a subject may not be aware of his or her concern for survival until after he or she (automatically) has detected a mismatch with that concern. Obviously, in the present experiments, the goal to gain the rewarded colour was consciously induced. Therefore, these experiments cannot be considered as the paradigmatic case for the unintentional processing of matches or mismatches with unconscious goals. Future efforts may be directed at the extension of our findings to valence that relates to unconscious or latent goals.

After we first observed the motivational affective priming effect (Moors \& De Houwer, 2001) we set up two lines of research to further test the limits of this effect. The present studies were set up to further examine the extent to which the motivational affective priming effect can be considered as being produced under automatic circumstances. In another line of research (Moors et al., 2004), we investigated to what extent we were successful in 
manipulating motivational valence as based on a true stimulus-goal comparison, instead of temporary intrinsic valence. The results of these studies strongly pleaded against an alternative explanation of the motivational affective priming effect according to which participants attached a temporary (for the duration of one trial) valence tag in memory to both possible primes immediately after the game rule was given but still before prime presentation, so that when the prime was actually presented, its stored valence tag could be simply retrieved.

The ensemble of these studies is highly relevant for recent multi-level process theories of emotion. Among appraisal theorists, there is a growing tendency to complement the structural hypotheses about the necessary and sufficient appraisal components for emotion elicitation and differentiation with hypotheses about the nature of the processes underlying appraisal. Whereas most theorists go no further than acknowledging the distinction between an automatic and a nonautomatic level of appraisal, only few theorists tackle the issue of pinpointing the formal characteristics of the appraisal processes that correspond to both levels of appraisal (Roseman \& Smith, 2001). Most theorists who do consider formal characteristics of appraisal processes seem to equate automatic appraisal to the process of memory retrieval of past emotional encounters, which are stored as schemata containing associations between events and elicited emotions (e.g., Power \& Dalgleish, 1997; Smith \& Kirby, 2001). Such a process has the advantage of leading to a fast outcome, but the disadvantage of lacking flexibility. Nonautomatic appraisals, on the other hand, have been equated to constructive reasoning processes, featured as slow but flexible (Smith \& Kirby, 2001). The present research has tried to take things one step further. In line with algorithm-based conceptions of automaticity (e.g., Anderson, 1992; Tzelgov, Yehene, Kotler, \& Alon, 2000), we propose that it is not only single-step memory retrieval that may take place in an automatic fashion, but also certain types of algorithm computation (constructive processes), such as the comparison operation between stimuli and concerns.

According to the dominant memory-based account of automaticity (e.g., Logan, 1988), initial stages of performance often rely on algorithm computation to produce an output. This output may (usually after some practice) become stored in memory so that future processing may bypass algorithm computation and rely entirely on memory retrieval to produce the same output. Automatization in this view is thus explained as the replacement of algorithmic processing by single-step memory retrieval. For example, when children learn to add pairs of digits, they initially count the units in both digits to produce the sum. After some practice, when an association is formed in memory between a pair of digits and their sum, children may immediately retrieve this sum from memory when presented with this pair of digits. Some authors have argued that, in addition to memory-based automaticity, there is also room for algorithm-based automaticity (e.g., Tzelgov et al., 2000). Automatization in this view corresponds to the gradual improvement or strengthening of algorithms or procedures. So the same algorithms responsible for the initial stages of performance are responsible for skilled automatic processing. Because the findings obtained with the motivational affective priming paradigm favour the automatic character of a stimulus-goal comparison process, which can be considered as a kind of algorithmic process, these findings are supportive of the existence of algorithm-based automaticity. The automaticity of intrinsic valence assessments as found in standard (i.e., intrinsic) affective priming studies, on the other hand, fits nicely into the conception of automaticity as single-step memory retrieval, because the stimuli used in these studies were often words or pictures that can be assumed 
to possess a fixed valence in memory. The development of both types of automaticity (memorybased and algorithm-based) is construed as largely dependent on practice. Whereas memory-based automaticity can only be installed in virtue of training on consistent data, algorithm-based automaticity can develop through practice with consistent procedures but variable data. Therefore, the latter type of automaticity allows for more flexibility than the former type. So according to an algorithm-based view on automaticity, flexible, constructive processes are not bound to be slow and nonautomatic.

Besides data versus procedure specificity, retrieval and comparison processes differ with respect to which part of the cognitive system they charge more. Whereas memory retrieval places a higher load on storage, algorithm computation puts a heavier burden on computation modules. On the supposition that the cognitive system tries to keep costs as low as possible, one might speculate that memory retrieval would be more opportune in circumstances in which goals and stimuli remain fairly stable (e.g., a predator is always trouble for a prey), whereas algorithm computation would be more beneficial when goals and/or stimuli change continuously. Examples of fluctuating goal states or standards are those deriving from the need for food intake or the need for stimulation (sensation seeking vs. safety). A comparison process does not only seem economic in the case of fluctuating standards but also in the case of fluctuating stimuli-that is, in the case in which stimuli, rather than being discrete isolatable entities, are gradually changing from moment to moment, and in which subtle changes in the stimulus configuration may lead to abrupt changes in emotional output. The following example may further illustrate this point. Consider the source goal of bodily safety, which may be in a heightened state when maneuvering with your bicycle in a hectic street. Imagine cars moving back and forth, coming closer and moving further away. Subtle changes in the position, speed, and direction of the cars may cause sudden fear responses, whereas other changes may set you back at ease or cause relief. Determining at which point a car is in a dangerous position (negative motivational valence) or not (positive or neutral motivational valence) can be easily construed as being guided by an algorithm in which the (weighed) sum of the values for the different parameters (position, speed, direction) is compared to some learned standard or threshold. When this threshold is exceeded, motivational valence is negative; below it, motivational valence is positive. In this type of situation, it is difficult to imagine that each particular combination of parameter values would have to be previously stored in memory (and tagged with valence) in order to get a quick appraisal of it as dangerous or safe. Obviously, the latter scenario would put a heavy weight on memory capacity. ${ }^{7}$ The reported studies portray a continuing effort to find evidence for the existence of a mechanism according to which events are weighed constantly against some standard or goal and that this type of process can take place in an automatic sense, just as can memory retrieval.

\footnotetext{
${ }^{7}$ However, suppose that only a few combinations of parameter values would be stored in memory and that new, never encountered combinations would have to trigger the stored ones on the basis of similarity. One obvious question may then be: Given that only subtle changes in the stimulus configuration are really dangerous (such as when a car that is driving next to you slightly turns in your direction), how does the system determine which change is similar enough to a stored configuration, and which change is not. In other words, it seems that some kind of threshold may be required even for a memory account to deliver sufficiently flexible outcomes. Any explanation invoking a threshold at some point requires a comparison between the input and that threshold.
} 
Support for the existence of stimulus-goal comparison processes is relevant not only for emotion theory but also for feedback control models of self-regulation developed within the domain of goal theory (e.g., Carver \& Scheier, 1981; Miller, Gallanter, \& Pribram, 1960). These models sketch a feedback loop in which informational input is first compared with a goal or standard represented in memory. A discrepancy between input and goal then induces compensatory behavior, aimed at undoing the discrepancy. Finally, the resulting state is again entered in the comparison function. This loop is repeated until no discrepancy is left. Recent studies have investigated the automatic nature of different steps in this feedback loop (see review by Moskowitz, Li, \& Kirk, 2004). One line of research is concerned with the automatic activation of goal representations (see Bargh, 1990; Gollwitzer \& Moskowitz, 1996). Another line of research is concerned with showing that the (explicit) frustration of a goal leads to automatic compensatory processes. For example, Moskowitz (2002) found that participants whose goal to be egalitarian was undermined directed their attention selectively to stimuli that provided an opportunity to repair the undermined goal. In these studies, it was not the mismatch itself that was concealed, but rather the way in which the mismatch exerted an influence on subsequent processing. The present studies were designed to investigate directly the automatic nature of the first step of the feedback loop, the one in which input is compared with goals. The present line of research therefore contributes to attempts to show that feedback loops of the type described above can run off automatically.

\section{REFERENCES}

Anderson, J. R. (1992). Automaticity and the ACT* theory. American fournal of Psychology, 105, 165-180.

Bargh, J. A. (1989). Conditional automaticity: Varieties of automatic influence in social perception and cognition. In J. S. Uleman \& J. A. Bargh (Eds.), Unintended thought (pp. 3-51). New York: Guilford Press.

Bargh, J. A. (1990). Auto-motives: Preconscious determinants of social interaction. In E. T. Higgins \& R. M. Sorrentino (Eds.), Handbook of motivation and cognition (Vol. 2, pp. 93-130). New York: Guilford.

Bargh, J. A. (1992). The ecology of automaticity. Toward establishing the conditions needed to produce automatic processing effects. American Fournal of Psychology, 105, 181-199.

Bargh, J. A. (1994). The four horsemen of automaticity: Awareness, intention, efficiency, and control in social cognition. In R. S. Wyer \& T. K. Srull (Eds.), Handbook of social cognition (Vol. 1, pp. 1-40). Hillsdale, NJ: Lawrence Erlbaum Associates, Inc.

Bargh, J. A. (1997). The automaticity of everyday life. In R. S. Wyer (Ed.), Advances in social cognition (Vol. 10, pp. 1-49). Mahwah, NJ: Lawrence Erlbaum, Associates, Inc.

Bargh, J. A., Chaiken, S., Govender, R., \& Pratto, F. (1992). The generality of the attitude activation effect. Fournal of Personality and Social Psychology, 62, 893-912.

Bargh, J. A., Chaiken, S., Raymond, P., \& Hymes, C. (1996). The automatic evaluation effect: Unconditional automatic activation with a pronunciation task. Journal of Experimental Social Psychology, 32, 104-128.

Bovens, N., \& Brysbaert, M. (1990). IBM PC/XT/AT and PS/2 Turbo Pascal timing with extended resolution. Behavior Research Methods, Instruments, and Computers, 22, 332-334.

Carver, C. S., \& Scheier, M. F. (1981). Attention and self-regulation: A control theory approach to human behavior. New York: Springer.

De Houwer, J., \& Eelen, P. (1998). An affective variant of the Simon paradigm. Cognition and Emotion, 12, 45-61.

Derryberry, D. (1988). Emotional influences on evaluative judgments: Roles of arousal, attention, and spreading activation. Motivation and Emotion, 12, 23-55.

Draine, S. C., \& Greenwald, A. G. (1998). Replicable unconscious semantic priming. Fournal of Experimental Psychology: General, 127, 286-303.

Ellsworth, P. C. (1991). Some implications of cognitive appraisal theories of emotion. In K. Strongman (Ed.), International reviem of studies on emotion (pp. 143-161). New York: Wiley. 
Fazio, R. H., Sanbonmatsu, D. M., Powell, M. C., \& Kardes, F. R. (1986). On the automatic activation of attitudes. Fournal of Personality and Social Psychology, 50, 229-238.

Fiske, S. T., \& Pavelchak, M. A. (1986). Category-based versus piecemeal-based affective responses: Developments in schema-triggered affect. In R. M. Sorrentino \& E. T. Higgins (Eds.), Handbook of motivation and cognition. (pp. 167-203). New York: Wiley.

Frijda, N. H. (1986). The emotions. New York: Cambridge University Press.

Frijda, N. H. (1993). The place of appraisal in emotion. Cognition and Emotion, 7, 357-387.

Frijda, N. H. (1994). Emotions require cognitions, even if simple ones. In P. Ekman \& R. J. Davidson (Eds.), The nature of emotion: Fundamental questions (pp. 197-202). New York: Oxford University Press.

Gollwitzer, P. M., \& Moskowitz, G. B. (1996). Goal effects on action and cognition. In E. T. Higgins \& A. W. Kruglanski (Eds.), Social psychology: Handbook of basic principles (pp. 361-399). New York: Guilford.

Hermans, D., Crombez, G., \& Eelen, P. (2000). Automatic attitude activation and efficiency: The fourth horseman of automaticity. Psychologica Belgica, 40, 3-22.

Hermans, D., \& De Houwer, J. (1994). Affective and subjective familiarity ratings of 740 Dutch words. Psychologica Belgica, 34, 115-139.

Hermans, D., De Houwer, J., \& Eelen, P. (1994). The affective priming effect: Automatic activation of evaluative information in memory. Cognition and Emotion, 8, 515-533.

Hermans, D., De Houwer, J., \& Eelen, P. (2001). A time course analysis of the affective priming effect. Cognition and Emotion, 15, 143-165.

Klauer, K. C., \& Musch, J. (2001). Does sunshine prime loyal? Affective priming in the naming task. Quarterly Journal of Experimental Psychology, 54A, 727-751.

Klauer, K. C., Roßnagel, C., \& Mush, J. (1997). List context effects in evaluative priming. Fournal of Experimental Psychology: Learning, Memory, and Cognition, 23, 246-255.

Lazarus, R. S. (1991). Emotion and adaptation. New York: Oxford University Press.

Logan, G. D. (1985). Skill and automaticity: Relations, implications, and future directions. Canadian Fournal of Psychology, 39, 367-386.

Logan, G. D. (1988). Toward an instance theory of automatization. Psychological Reviem, 95, 492-527.

Miller, G. A., Galanter, E., \& Pribram, K. (1960). Plans and the structure of behavior. New York: Holt.

Mogg, K., Bradley, B. P., \& Williams, R. (1995). Attentional bias in anxiety and depression: The role of awareness. British Journal of Clinical Psychology, 34, 17-36.

Moors, A., \& De Houwer, J. (2001). Automatic appraisal of motivational valence: Motivational affective priming and Simon effects. Cognition and Emotion, 15, 749-766.

Moors, A., De Houwer, J., \& Eelen, P. (2004). Automatic stimulus-goal comparisons: Support from motivational affective priming studies. Cognition and Emotion, 18, 29-54.

Moskowitz, G. B. (2002). Preconscious effects of temporary goals on attention. Fournal of Experimental Social Psychology, 83, 1029-1050.

Moskowitz, G. B., Li, P., \& Kirk, E. R. (2004). The implicit volition model: On the preconscious regulation of temporarily adopted goals. In M. Zanna (Ed.), Advances in experimental social psychology (Vol. 34, pp. 317-414). San Diego, CA: Academic Press.

Natsoulas, T. (1981). Basic problems of consciousness. Fournal of Personality and Social Psychology, 41, $132-178$.

Neely, J. H. (1977). Semantic priming and retrieval from lexical memory: Roles of inhibitionless spreading activation and limited-capacity attention. Fournal of Experimental Psychology: General, 106, 226-254.

Orthony, A., Clore, G. L., \& Collins, A. (1988). The cognitive structure of emotions. London: Cambridge University Press.

Power, M., \& Dalgleish, T. (1997). Cognition and emotion: From order to disorder. Hove, UK: Psychology Press.

Roseman, I. J., \& Smith, C. A. (2001). Appraisal theory: Overview, assumptions, varieties, controversies. In K. R. Scherer, A. Schorr, \& T. Johnstone (Eds.), Appraisal processes in emotion (pp. 3-34). New York: Oxford University Press.

Rothermund, K. (2003). Motivation and attention: Incongruent effects of feedback on the processing of valence. Emotion, 3, 223-238.

Scherer, K. R. (1984). On the nature and function of emotions: A component process approach. In K. R. Scherer \& P. Ekman (Eds.), Approaches to emotion (pp. 293-317). Hillsdale, NJ: Lawrence Erlbaum Associates, Inc.

Scherer, K. R. (1988). Criteria for emotion-antecedent appraisal: A review. In V. Hamilton, G. H. Bower, \& N. H Frijda (Eds.), Cognitive perspectives on emotion and motivation (pp. 89-126). Dordrecht, The Netherlands: Kluwer. 
Scherer, K. R. (1993). Neuroscience projections to current debates in emotion psychology. Cognition and Emotion, 7, 1-41.

Scherer, K. R. (1994). An emotion's occurrence depends on the relevance of an event to the organism's goal/need hierarchy. In P. Ekman \& R. J. Davidson (Eds.), The nature of emotion: Fundamental questions (pp. 227-231). New York: Oxford University Press.

Shiffrin, R. M. (1988). Attention. In R. C. Atkinson, R. J. Hernstein, G. Lindzey, \& R. D. Luce (Eds.), Stevens' handbook of experimental psychology (Vol. 2, pp. 739-811). New York: Wiley.

Smith, C. A., \& Kirby, L. D. (2001). Toward delivering on the promise of appraisal theory. In K. R. Scherer, A. Schorr, \& T. Johnstone (Eds.), Appraisal processes in emotion (pp. 121-138). New York: Oxford University Press.

Spruyt, A., Hermans, D., De Houwer, J., \& Eelen, P. (2002). On the nature of the affective priming effect: Affective priming of naming responses. Social Cognition, 20, 227-256.

Tzelgov, J., Yehene, V., Kotler, L., \& Alon, A. (2000). Automatic comparisons of artificial digits never compared: Learning linear ordering relations. Journal of Experimental Psychology: Learning, Memory, and Cognition, 26, $103-120$.

Williams, J. M. G., Mathews, A., \& MacLeod, C. (1996). The emotional Stroop task and psychopathology. Psychological Bulletin, 120, 3-24.

Original manuscript received 26 fanuary 2004

Accepted revision received 28 April 2004

PrEviem proof published online 01 November 2004

\section{APPENDIX}

\section{Experiment 1}

Positive experimental targets charmant (charming) gelukkig (happy) oprecht (sincere)

dankbaar (grateful)

slim (clever)

blij (glad)

zacht (soft)

prettig (pleasant)

opgetogen (elated)

betrouwbaar (reliable)
Negative experimental targets

vals (false)

wreed (cruel)

gemeen (mean)

vervelend (annoying)

brutaal (bold)

egoïstisch (egoistic)

agressief (aggressive)

laf (cowardly)

hatelijk (hateful)

vijandig (hostile) 


\section{Experiment 2}

$\begin{array}{ll}\text { Experimental primes: Animals } & \text { Professions } \\ \text { walrus (walrus) } & \text { radioloog (radiologist) } \\ \text { dromedaris (dromedary) } & \text { schilder (painter) } \\ \text { ijsbeer (icebear) } & \text { ober (waiter) } \\ \text { salamander (salamander) } & \text { tuinman (gardener) } \\ \text { eekhoorn (squirrel) } & \text { apotheker (pharmacist) } \\ \text { pony (pony) } & \text { actrice (actress) } \\ \text { hamster (hamster) } & \text { kinesist (physiotherapist) } \\ \text { antilope (antilope) } & \text { architect (architect) } \\ \text { kikker (frog) } & \text { oogarts (eye-specialist) } \\ \text { kangoeroe (kangaroo) } & \text { postbode (postman) } \\ \text { nijlpaard (hipopotame) } & \text { typiste (typist) } \\ \text { schildpad (turtle) } & \text { ingenieur (engineer) } \\ \text { giraf (giraffe) } & \text { geoloog (geologist) } \\ \text { kameel (camel) } & \text { sportman (sportsman) } \\ \text { walvis (whale) } & \text { zanger (singer) } \\ \text { hagedis (lizard) } & \text { chirurg (surgeon) } \\ \text { zwaluw (swallow) } & \text { dietist (dietician) } \\ \text { kalkoen (turkey) } & \text { detectieve (detective) } \\ \text { papegaai (parrot) } & \text { journalist (journalist) } \\ \text { parkiet (parakeet) } & \text { advocaat (lawyer) } \\ & \\ \text { Experimental targets: Positive } & \text { Negative } \\ \text { vrede (peace) } & \text { ziekte (disease) } \\ \text { bloemen (flowers) } & \text { ongeluk (misfortune/accident) } \\ \text { zon (sun) } & \text { vuilnis (garbage) } \\ \text { liefde (love) } & \text { angst (fear) } \\ \text { geschenk (gift) } & \text { paniek (panic) } \\ \text { lach (smile) } & \text { dood (death) } \\ \text { wens (wish) } & \text { pijn (pain) } \\ \text { regenboog (rainbow) } & \text { oorlog (war) } \\ \text { vakantie (holidays) } & \text { misdaad (crime) } \\ \text { feest (party) } & \text { verdriet (sorrow) } \\ & \end{array}$

